\title{
Structure and Multistage Martensite Transformation in Nanocrystalline Ti-50.9Ni Alloy
}

\author{
Tamara M. Poletika ${ }^{1, *}$, Svetlana L. Girsova ${ }^{1}$, Aleksander I. Lotkov ${ }^{1}{ }^{1}$, Andrej N. Kudryachov ${ }^{2}$ \\ and Natalya V. Girsova ${ }^{1}$ \\ 1 Institute of Strength Physics and Materials Science SB RAS, 634055 Tomsk, Russia; girs@ispms.tsc.ru (S.L.G.) \\ lotkov@ispms.tsc.ru (A.I.L.); girsova@ispms.tsc.ru (N.V.G.) \\ 2 Angioline Research, 630559 Novosibirsk, Russia; kudryashovan@gmail.com \\ * Correspondence: poletm@ispms.tsc.ru; Tel.: +7-909-548-7297
}

Citation: Poletika, T.M.; Girsova S.L.; Lotkov, A.I.; Kudryachov, A.N.; Girsova, N.V. Structure and Multistage Martensite Transformation in Nanocrystalline Ti-50.9Ni Alloy. Metals 2021, 11, 1262. https:// doi.org/10.3390/met11081262

Academic Editor: Elena Pereloma

Received: 25 June 2021

Accepted: 9 August 2021

Published: 10 August 2021

Publisher's Note: MDPI stays neutral with regard to jurisdictional claims in published maps and institutional affiliations.

Copyright: (c) 2021 by the authors. Licensee MDPI, Basel, Switzerland. This article is an open access article distributed under the terms and conditions of the Creative Commons Attribution (CC BY) license (https:/ / creativecommons.org/licenses/by/ $4.0 /)$.

\begin{abstract}
An electron microscopic study of the evolution of the size, morphology, and spatial distribution of coherent $\mathrm{Ti}_{3} \mathrm{Ni}_{4}$ particles with a change in the aging temperature in a nanocrystalline (NC) Ti-50.9 at \% Ni alloy with an inhomogeneous grain-subgrain B2-austenitic nanostructure has been carried out. It was found that with an increase in the aging temperature, along with a change in the size and shape of $\mathrm{Ti}_{3} \mathrm{Ni}_{4}$ nanoparticles, their spatial distribution changes from location at dislocations to precipitates at subboundaries. Research has shown that the presence of different types of internal interfaces in the nanostructure contributes to the heterogeneous distribution of coherent $\mathrm{Ti}_{3} \mathrm{Ni}_{4}$ nanoparticles in the volume of the $\mathrm{B} 2$ matrix, which is associated with the precipitation of particles in the region of low-angle subboundaries and the suppression of the $\mathrm{Ti}_{3} \mathrm{Ni}_{4}$ precipitation in nanograins with high-angle boundaries. The difference in the structural-phase state of nanograins and subgrains regions is the main reason for the implementation of the anomalous R-phase transformation effect in the sequence of multistage martensitic transformations $\mathrm{B} 2 \leftrightarrow \mathrm{R} \leftrightarrow \mathrm{B} 19^{\prime}$.
\end{abstract}

Keywords: nanocrystalline TiNi alloy; annealing; grain-subgrain structure; $\mathrm{Ti}_{3} \mathrm{Ni}_{4}$ particles; martensite transformations

\section{Introduction}

Nanocrystalline TiNi alloys with unique properties of shape memory effect and superelasticity, due to the reversible transformation between B2-austenite and B19' martensite, have high strength and functional stability and are widely used in medicine [1,2]. Their representatives in biomedicine are Ni-rich TiNi alloys, which are aged with the formation of coherent $\mathrm{Ti}_{3} \mathrm{Ni}_{4}$ particles [1-3]. Such precipitates in TiNi polycrystals can change the path of martensitic transformations from $\mathrm{B} 2 \rightarrow \mathrm{B} 19^{\prime}$ to the sequence of transformations through the transition R-phase: $\mathrm{B} 2 \rightarrow \mathrm{R} \rightarrow \mathrm{B} 19^{\prime}$ [3-5]. This is mainly due to inhomogeneous $\mathrm{Ti}_{3} \mathrm{Ni}_{4}$ particles distribution in B2-austenite grains and the associated difference in the Ni content between B2-austenite grain volumes and boundaries [6,7]. However, in NC TiNi alloys with a large volume fraction of interfaces, the cause of multistage transformations is unclear, and the formation of coherent $\mathrm{Ti}_{3} \mathrm{Ni}_{4}$ particles as well as their spatial distribution is poorly understood. This is largely due to the lack of data on the localization of coherent $\mathrm{Ti}_{3} \mathrm{Ni}_{4}$ particles in the nanostructure of TiNi alloys due to the complexity of their detection and certification in NC material. In addition, the study of NC TiNi alloys is complicated by the necessity of accounting for grain refinement and associated increase in critical martensite shear stresses [8], possible suppression of B2-austenite solid solution decomposition in nanograins [9], and high defect density in the nanostructure after severe deformation [10]. Another important factor is that the nanostructure of TiNi alloys after cold deformation is highly inhomogeneous. For example, a mixed grain-subgrain B2 structure is typical of textured TiNi after severe cold deformation [11]. Such a structure is observed in semifinished products (wires, thin-walled tubes, etc.) used for manufacturing various medical 
devices. The purpose of this work is to better understand the effect of the size and spatial distribution of $\mathrm{Ti}_{3} \mathrm{Ni}_{4}$ particles in grain-subgrain nanostructure of an aged Ti-50.9 at \% $\mathrm{Ni}$ alloy on the multistage character of martensite transformations. This knowledge can be used to fine-tune the interval of martensitic transformations in NC Ni-rich TiNi alloy tubing in the process of medical implants manufacturing.

\section{Materials and Methods}

The test material was a commercial nanocrystalline TiNi alloy with a Ni content of 50.9 at \% (Vascotube GmbH, Birkenfeld, Germany). The tubular samples cut from microtubes for medical stents were annealed at $300{ }^{\circ} \mathrm{C}$ (low-temperature aging) and $400{ }^{\circ} \mathrm{C}$ (region of the highest rate of $\mathrm{Ti}_{3} \mathrm{Ni}_{4}$ precipitation) for $1 \mathrm{~h}$ with further water quenching at room temperature. These aging treatments will allow the precipitation of $\mathrm{Ti}_{3} \mathrm{Ni}_{4}$ particles differing in size and morphology. The start and finish temperatures of direct and reverse B2 $\leftrightarrow \mathrm{R} \leftrightarrow \mathrm{B} 19^{\prime}$ transformations were determined by electrical resistivity measurements. In all specimens, the sequence of direct and reverse martensite transformations was $B 2 \leftrightarrow R \leftrightarrow B 19^{\prime}$. The critical start temperatures of $\mathrm{B} 2 \rightarrow \mathrm{R}\left(\mathrm{T}_{\mathrm{R}}\right)$ as well as the start and finish temperatures of $\mathrm{R} \leftrightarrow \mathrm{B} 19^{\prime}\left(\mathrm{M}_{\mathrm{S}}, \mathrm{M}_{\mathrm{F}}, \mathrm{A}_{\mathrm{S}}, \mathrm{A}_{\mathrm{F}}\right)$ determined by resistivity measurements are presented in Table 1. The features of $\mathrm{B} 2 \leftrightarrow \mathrm{R} \leftrightarrow \mathrm{B} 19^{\prime}$ transformations were analyzed on a NETZSCH DSC 404 F1 differential scanning calorimeter with a heating and cooling rate of $10 \mathrm{~K} / \mathrm{min}$.

Table 1. Martensite transformation temperatures in nanocrystallineTi-50.9Ni alloy.

\begin{tabular}{cccccc}
\hline Temperature & $\mathbf{T}_{\mathbf{R}},{ }^{\circ} \mathbf{C}$ & $\mathbf{M}_{\mathbf{S}},{ }^{\circ} \mathbf{C}$ & $\mathbf{M}_{\mathbf{F}},{ }^{\circ} \mathbf{C}$ & $\mathbf{A}_{\mathbf{S}},{ }^{\circ} \mathbf{C}$ & $\mathbf{A}_{\mathbf{F}},{ }^{\circ} \mathbf{C}$ \\
\hline Initial & 7 & -74 & -140 & -45 & -26 \\
\hline $300{ }^{\circ} \mathbf{C}$ & 22 & -50 & -130 & -37 & -14 \\
\hline $400{ }^{\circ} \mathbf{C}$ & 33 & -30 & -115 & -2 & 15 \\
\hline
\end{tabular}

The structure of the specimens cut along the microtube axis was studied on a JEOL JEM 2100 transmission electron microscope. The preparation of thin foils included grinding, mechanical polishing to a thickness of $0.1 \mathrm{~mm}$, and ion thinning on a JEOL EM 09100IS ion slicer. The average size of grains and subgrains was determined by measuring the average diameter of no less 100 grains on bright- and dark-field images. A comparative analysis of the size of the $\mathrm{Ti}_{3} \mathrm{Ni}_{4}$ precipitations in samples heat-treated at various temperatures was carried out mainly on dark-field images.

\section{Results}

\subsection{Microstructure Characterization}

The initial alloy has an inhomogeneous hierarchical B2-austenite nanostructure with elements of two scales: conglomerates of slightly misoriented nanosubgrains of micron sizes and nanograins with high-angle boundaries, which provides a wide range of internal interfaces (Figure 1). There are two types of nanograins: (i) dislocation-containing nanograins formed under severe deformation and further annealing and (ii) dislocationfree nanograins crystallized from amorphous state [11]. The average size of dislocation-free nanograins with high-angle boundaries is $70 \mathrm{~nm}$. In subgrains of size $40-60 \mathrm{~nm}$, a high dislocation density is observed. Such subgrains, having imperfect low-angle boundaries azimuthally misoriented by less than $3^{\circ}$, form regions of up to $800 \mathrm{~nm}$ (Figure $1 \mathrm{~b}$ ). On selected area electron diffraction (SAED) patterns, the grain-subgrain structure is represented mostly by circular point reflections. In addition to B2-austenite reflections, there are individual reflections identifiable as $\mathrm{R}$-phase and $\mathrm{Ti}_{3} \mathrm{Ni}_{4}$-phase reflections. 


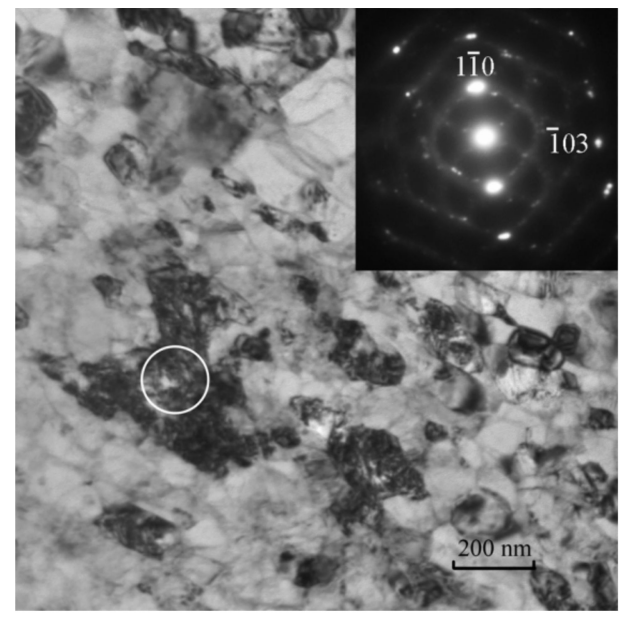

(a)

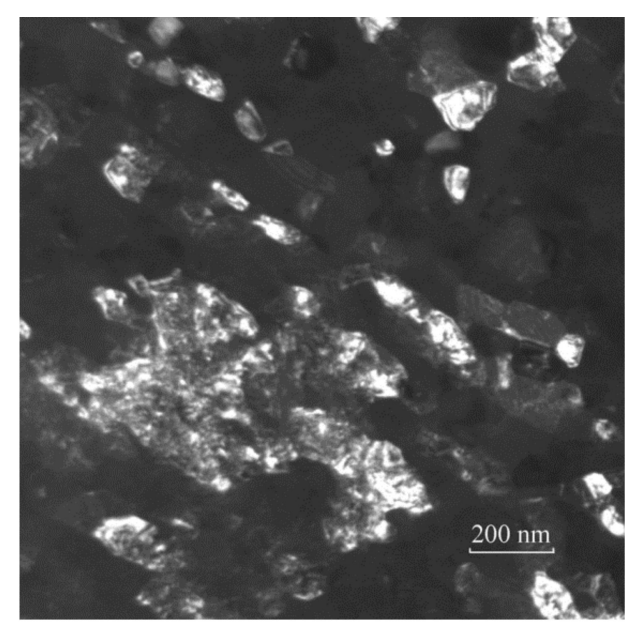

(b)

Figure 1. Bright-field image of mixed grain-subgrain structure with a submicron subgrain region, corresponding SAED pattern from the circled region, zone axis [331] (a), and dark-field image (b) in B2-austenite reflection (11̄0).

Figure 2 shows the structure of the alloy after annealing at $300{ }^{\circ} \mathrm{C}$. Such low-temperature aging involves recovery and polygonization processes, dislocation density reduction, and dislocation rectification of low-angle boundaries, but the size of grains and subgrains remains, on average, unchanged. In the structure, coherent $\mathrm{Ti}_{3} \mathrm{Ni}_{4}$ particles smaller than $10 \mathrm{~nm}$ precipitate (Figure 2a,b), which is characteristic of the initial stage of B2 phase decomposition in TiNi during low-temperature aging [12]. Such particles precipitate mostly inside subgrains and at dislocations, showing weak reflections in positions $1 / 7$ along the B2 lattice directions <321> (Figure 2c) and a "coffee bone" contrast induced by elastic distortion fields (Figure 2b). For comparison, dislocation-free grains are shown (Figure 2e,f), which are usually several tens of nanometers in size. No dislocations were found in these nanograins at admissible tilt angles. In addition, such grains did not show a clear TEM diffraction of $\mathrm{Ti}_{3} \mathrm{Ni}_{4}$ precipitates. Figure $2 \mathrm{c}$ shows that on the SAED patterns, the diffraction spots occurring at $1 / 3<110>$ B2 are observed, indicating the formation of an R-phase. This is consistent with the data in Table 1, which show that the B2- and R-phases coexist at room temperature. As can be seen on the dark-field image in a $(\overline{1} 0 \overline{2})$ reflex (Figure 2d), disperse and imperfect morphology of R-martensite is observed.

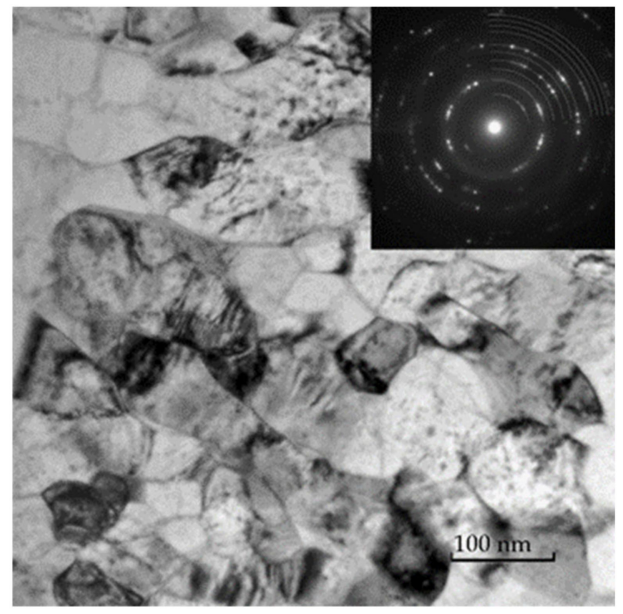

(a)

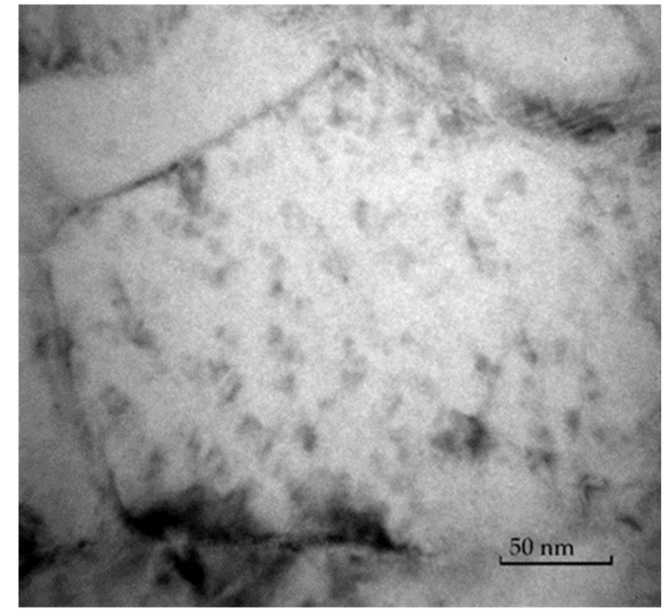

(b)

Figure 2. Cont. 


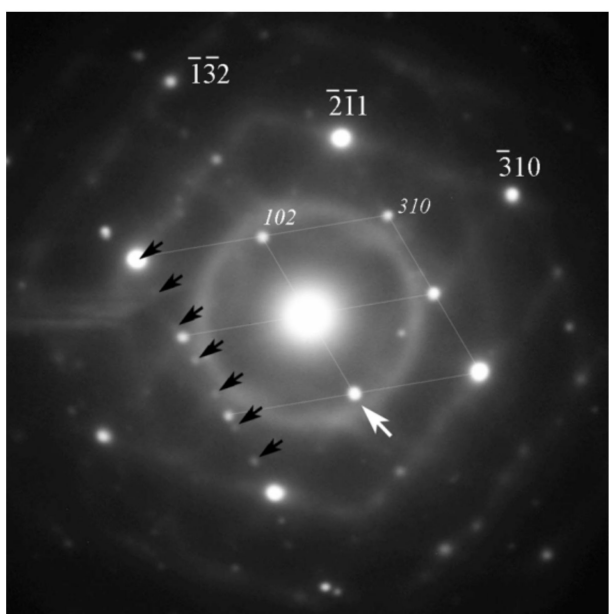

(c)

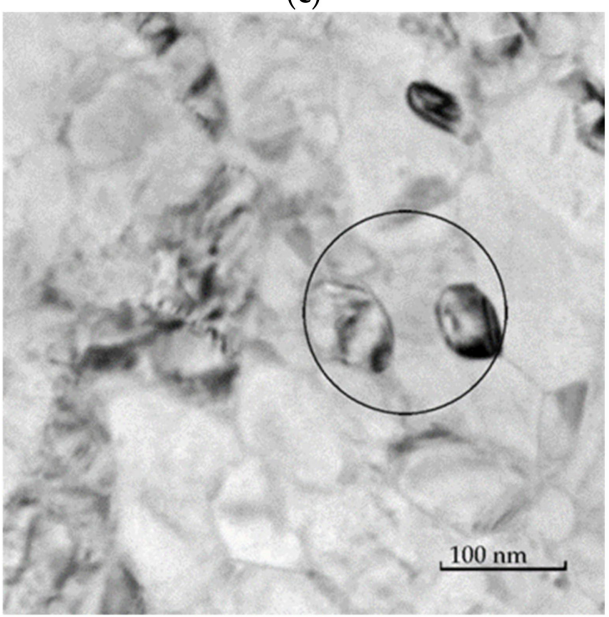

(e)

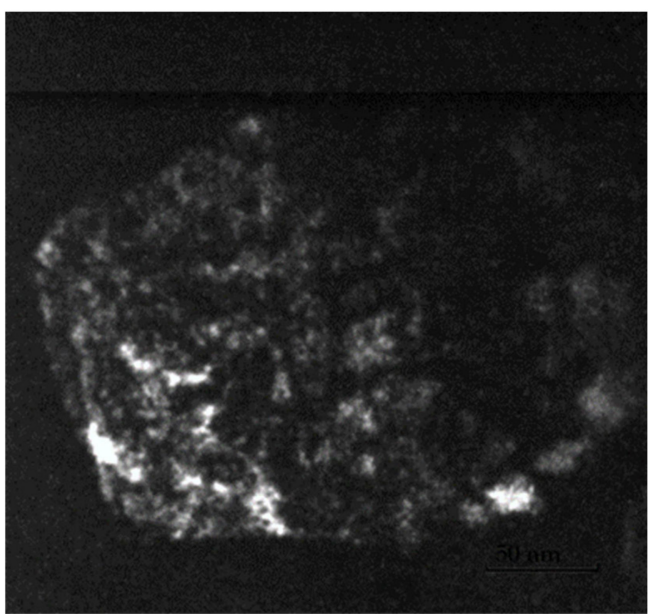

(d)

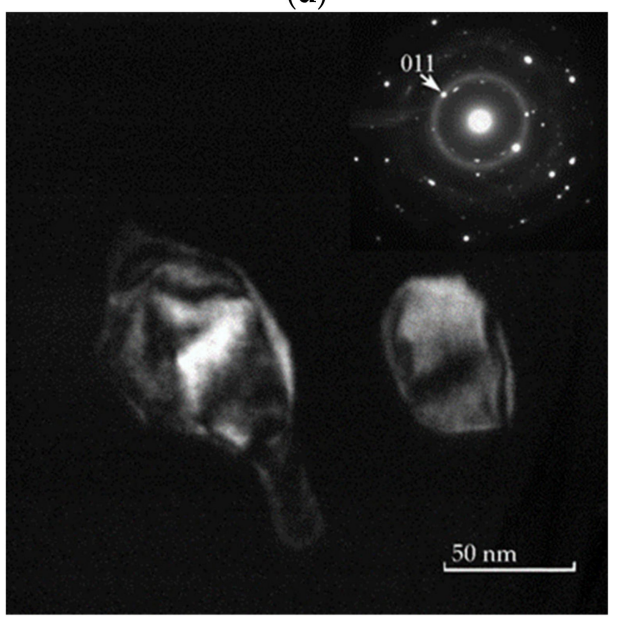

(f)

Figure 2. Structure of Ti-50.9Ni after annealing at $300{ }^{\circ} \mathrm{C}$ : (a) bright-field image of subgrains and corresponding SAED pattern, arcs correspond to the positions of reflections of B2, (b) bright-field image of large grain with "coffee bone" contrast indicative of the presence of coherent $\mathrm{Ti}_{3} \mathrm{Ni}_{4}$ particles, (c) corresponding SAED pattern showing weak reflections of $\mathrm{Ti}_{3} \mathrm{Ni}_{4}$ particles in positions $1 / 7$ along the $\mathrm{B} 2$ lattice directions $<321>$ (dark arrows), zone axis [135], the R-phase reciprocal lattice section is indicated by white lines, (d) R-phase dark-field image in a $(\overline{1} 0 \overline{2})$ reflection indicated by white arrows on (c), $(\mathbf{e}, \mathbf{f})$ bright-field image of dislocation-free grains and corresponding dark-field in (011) reflection of B2 on SAED pattern.

The precipitation of $\mathrm{Ti}_{3} \mathrm{Ni}_{4}$ particles at dislocations during low-temperature annealing is due to the low volumetric diffusion of atoms and the predominance of diffusion of atoms along dislocation tubes. It should be noted that this type of precipitate is found in dislocation-containing nanograins and is not found in dislocation-free nanograins. Such $\mathrm{Ti}_{3} \mathrm{Ni}_{4}$ nanoparticles are rarely observed in grain boundary-subboundary regions because the low aging temperature $\left(300{ }^{\circ} \mathrm{C}\right)$ does not allow $\mathrm{Ni}$ atoms to diffuse from internal grain-subgrain volumes to their boundaries. The fine $\mathrm{Ti}_{3} \mathrm{Ni}_{4}$ particles decorate the few dislocations present in nanograins. Our results agree with data on polycrystalline TiNi alloys whose structure after low-temperature annealing $\left(<330^{\circ} \mathrm{C}\right)$ contains a large amount of coherent spherical nanoparticles of diameter $<10 \mathrm{~nm}[12,13]$.

Annealing at $400{ }^{\circ} \mathrm{C}$ decreases the dislocation density and slightly widens the size range of polygonized nanograins, i.e., no recrystallization occurs. At the stage of recovery, dislocations inside subgrains are redistributed such that some of them are annihilated and others escape to low-angle subboundaries. As a result, the subboundaries change 
their shape from linear after annealing at $300{ }^{\circ} \mathrm{C}$ (Figure $2 \mathrm{a}, \mathrm{b}$ ) to convex after annealing at $400{ }^{\circ} \mathrm{C}$ (Figure 3). Their bright-field images reveal a diffuse diffraction contrast (Figure 3 ) which can be indicative of their nonequilibrium state $[14,15]$ due to substantial B2 matrix distortion in elastic stress fields induced by excess dislocations and by coherent $\mathrm{Ti}_{3} \mathrm{Ni}_{4}$ particles formed at subgrain boundaries [15].

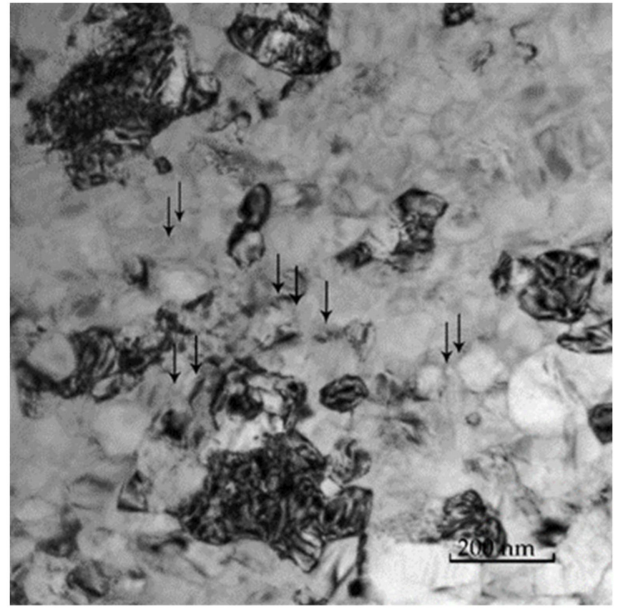

(a)

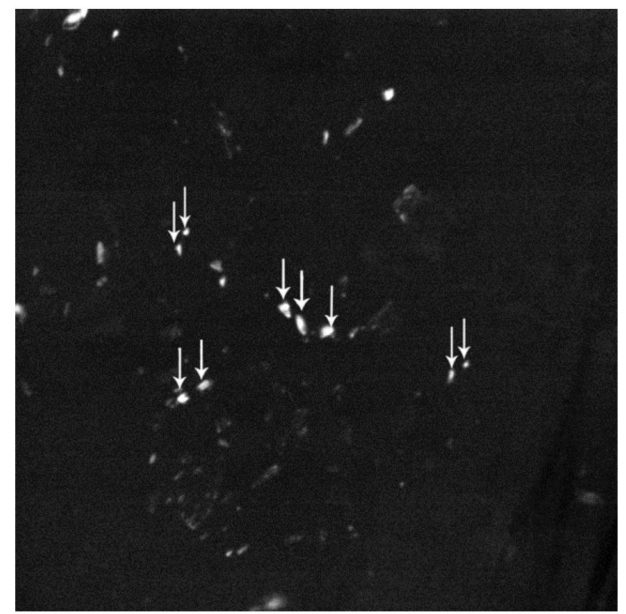

(b)

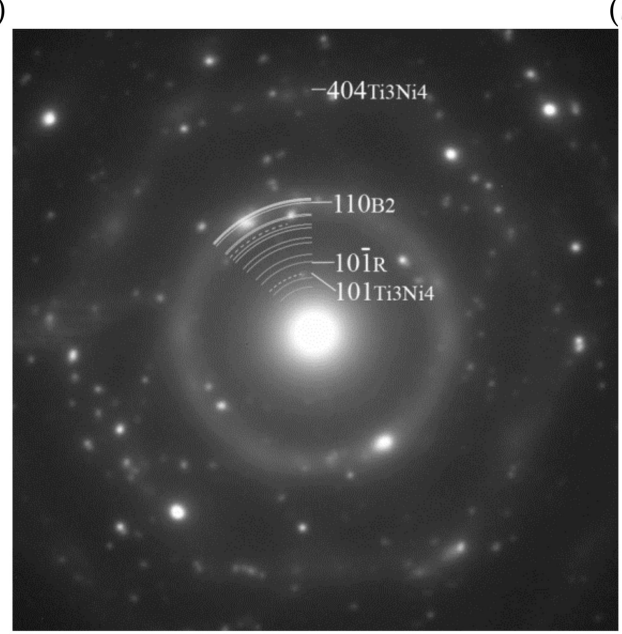

(c)

Figure 3. Subgrain structure of Ti-50.9Ni with $\mathrm{Ti}_{3} \mathrm{Ni}_{4}$ particles after annealing at $400{ }^{\circ} \mathrm{C}$ : (a) brightfield images with arrows for particle lines near low-angle boundaries, (b) dark field in reflection $\{101\}$ of $\mathrm{Ti}_{3} \mathrm{Ni}_{4}$ particles, (c) SAED pattern, solid and dash arcs correspond to positions of reflections of $\mathrm{R}$-and $\mathrm{Ti}_{3} \mathrm{Ni}_{4}$-phases.

Under annealing at $400{ }^{\circ} \mathrm{C}$, the alloy undergoes intense aging due to intense $\mathrm{Ti}_{3} \mathrm{Ni}_{4}$ precipitation at $400-450{ }^{\circ} \mathrm{C}$ [16]. As can be seen from Figure 3c, its microdiffraction patterns reveal numerous point reflections of $\mathrm{R}$ martensite and $\mathrm{Ti}_{3} \mathrm{Ni}_{4}$ particles precipitated mainly in nonequilibrium subboundary regions.

The shape of $\mathrm{Ti}_{3} \mathrm{Ni}_{4}$ particles is close to lenticular with a lateral dimension of up to $5 \mathrm{~nm}$ and length of up to $20 \mathrm{~nm}$. Their tendency to line up in rows in the planes $\{111\}$ is observed. In Figure 3a, one can identify lines of $\mathrm{Ti}_{3} \mathrm{Ni}_{4}$ particles adjacent to subboundaries. Such an arrangement points to their autocatalytic character, which compensates the nucleation and growth energy of $\mathrm{Ti}_{3} \mathrm{Ni}_{4}$ [5]. The morphology of $\mathrm{Ti}_{3} \mathrm{Ni}_{4}$ particles is such that they can lose their lenticular shape caused by the lattice mismatch between $\mathrm{Ti}_{3} \mathrm{Ni}_{4}$ and $\mathrm{B} 2$ matrix [5]. Apparently, this is due to their asymmetric growth under the action of high inhomogeneous stress fields near subboundaries [5,17]. In our analysis, no lenticular $\mathrm{Ti}_{3} \mathrm{Ni}_{4}$ particles and lines were found in nanograins with high-angle boundaries, and this agrees with the 
conclusion that in TiNi aged at $400{ }^{\circ} \mathrm{C}$, the $\mathrm{B} 2$ phase decomposition with the formation of $\mathrm{Ti}_{3} \mathrm{Ni}_{4}$ particles in nanograins smaller than $150 \mathrm{~nm}$ is suppressed [9].

At room temperature, the alloy aged at $400{ }^{\circ} \mathrm{C}$ has a two-phase state: B2-austenite and $\mathrm{R}$-phase (Table 1). Considering that the grain and subgrain sizes remain unchanged, we think that the intense formation of $\mathrm{Ti}_{3} \mathrm{Ni}_{4}$ effectively decreases the $\mathrm{Ni}$ concentration in the $B 2$ matrix and increases the temperature of $\mathrm{B} 2 \leftrightarrow \mathrm{R}$ transformations $\left(\mathrm{T}_{\mathrm{R}}\right)$. The R-phase is dispersed into nanodomains, and its morphology is mostly imperfect (Figure $4 \mathrm{~b}$ ), which is due to the effect of elastic stress fields created by coherent $\mathrm{Ti}_{3} \mathrm{Ni}_{4}$ particles and dislocations. This phase is present in substructural regions and is not present in nanograins free of dislocations and particles. The transformation to the R-phase can cover the whole volume of individual subgrains and their groups (Figure 4).

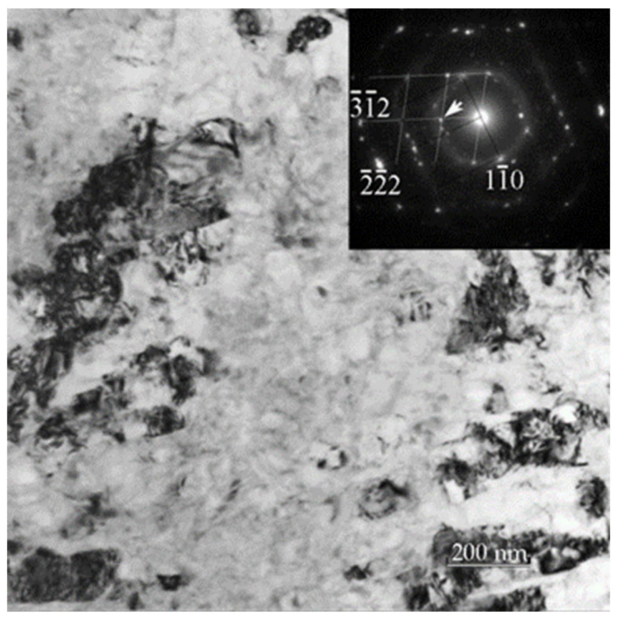

(a)

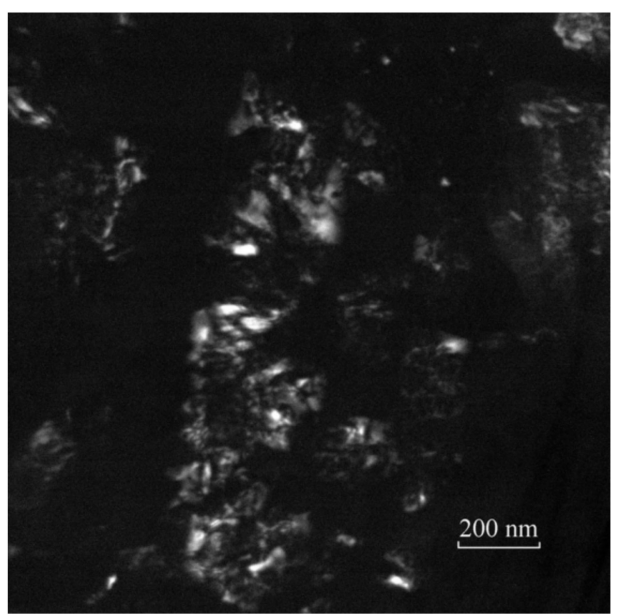

(b)

Figure 4. R-phase in substructure: (a) bright-field image with complex contrast created by $\mathrm{Ti}_{3} \mathrm{Ni}_{4}$ particles, dislocations, and R-phase; corresponding microdiffraction pattern, zone axis [112], reflections from B2-phase are indexed, R-phase reciprocal lattice section are indicated by white lines (b) corresponding dark-field image in R-phase reflection ( $(\overline{3} 10)$ are indicated by white arrow on (a) with visible phase dispersion.

\subsection{Multistage Martensite Transformations}

Figure 5 shows calorimetric curves for NC Ti-50.9Ni alloy in the initial state and aged at $300{ }^{\circ} \mathrm{C}$ and $400{ }^{\circ} \mathrm{C}$. DSC peaks were interpreted using the results of measuring the temperatures of martensitic transformations by the thermoresistometry method, presented in Table 1, as well as the above results of structural studies of aged alloy samples by the TEM method. On cooling, the initial NC alloy reveals two diffuse exothermal peaks due to direct $\mathrm{B} 2 \rightarrow \mathrm{R}$ and $\mathrm{B} 2 \rightarrow \mathrm{B}^{\prime} 9^{\prime}$ transformations characteristic of aged TiNi alloys with defect B2 structure [18]. On heating, it shows a single broad endothermal peak corresponding to $\mathrm{B}_{1} 9^{\prime} \rightarrow \mathrm{R} \rightarrow \mathrm{B} 2$ transformations. The latent heats $\Delta \mathrm{H}$ of the $\mathrm{B} 2 \rightarrow \mathrm{R}$ and the $\mathrm{R} \rightarrow \mathrm{B} 19^{\prime}$ transformations were 3.8 and $2 \mathrm{~J} \mathrm{~g}^{-1}$, respectively. The $\mathrm{R} \rightarrow \mathrm{B} 19^{\prime}$ transformation is significantly suppressed, showing a low and broad exothermal peak. Thus, we can assume that the sample exhibited a single-stage $\mathrm{B} 2 \rightarrow \mathrm{R}$ transformation on cooling and a single stage $\mathrm{R} \rightarrow \mathrm{B} 2$ transformation on heating. It can be seen that after aging at $300^{\circ} \mathrm{C}$, the peaks on the DSC curves represent $\mathrm{B} 2 \rightarrow \mathrm{R}$ and $\mathrm{B} 2 \rightarrow \mathrm{B} 19^{\prime}$ on cooling and $\mathrm{B} 19^{\prime} \rightarrow \mathrm{R}$ and $\mathrm{R} \rightarrow \mathrm{B} 2$ on heating, which are the normal two-stage martensitic transformations for aged $\mathrm{Ti}-\mathrm{Ni}$ alloys. The corresponding value of $\Delta \mathrm{H}_{\mathrm{A} \rightarrow \mathrm{R}}$ was $5.4 \mathrm{~J} \mathrm{~g}^{-1}$ and that of $\Delta \mathrm{H}_{\mathrm{R} \rightarrow \mathrm{A}}$ was $5.3 \mathrm{~J}$ $\mathrm{g}^{-1}$. These values are in the range of $1-6 \mathrm{~J} \mathrm{~g}^{-1}$ for $\mathrm{B} 2 \leftrightarrow \mathrm{R}$ transformations [19]. The diffuse nature of these peaks does not allow a sufficient accuracy the temperature hysteresis, but the estimate gives a value of about $6^{\circ} \mathrm{C}$, which is the typical characteristic of R-phase transformation. Thus, it can be deduced that these DSC peaks represent $B 2 \rightarrow R$ and $R \rightarrow B 2$, respectively, which is also close to the data presented in Table 1. 


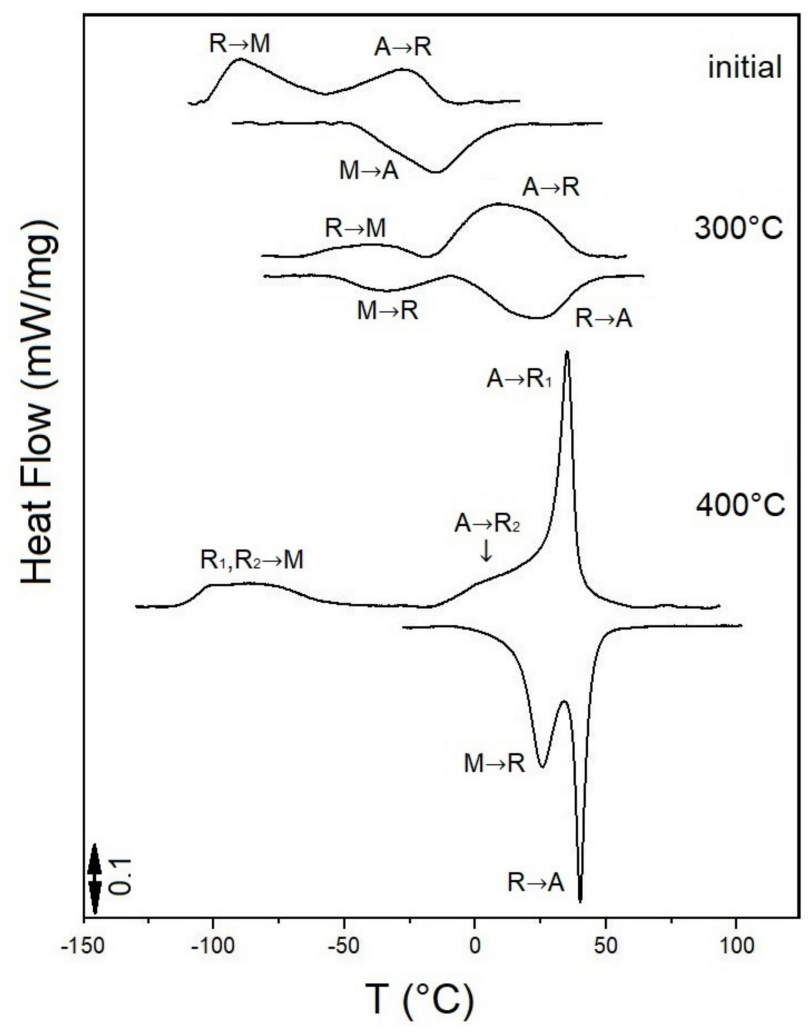

Figure 5. Calorimetric curves for cooling (upper traces) and heating (lower traces) of Ti-50.9Ni in initial state and annealed at $300{ }^{\circ} \mathrm{C}$ and $400{ }^{\circ} \mathrm{C}$ for $1 \mathrm{~h}$.

Another form of calorimetric curves is observed for the alloy aged at $400{ }^{\circ} \mathrm{C}$ (Figure 5). On cooling, the $\mathrm{B} 2 \rightarrow \mathrm{R}$ transformation occurred over a broad temperature range. As can be seen from Figure 5, the narrow B2 $\rightarrow$ R peak has a shoulder on the left, which can be interpreted as at least one additional peak. The bases of the peaks merge, giving no way to separate additional peaks with sufficient accuracy. The combined latent heat of this peak is $6.8 \mathrm{~J} \mathrm{~g}^{-1}$. As shown above, aging at $400{ }^{\circ} \mathrm{C}$ leads to intense $\mathrm{Ti}_{3} \mathrm{Ni}_{4}$ particles precipitation that shifts the $\mathrm{B} 2 \rightarrow \mathrm{R}$ transformation to higher temperatures. As a result, the R-phase is stabilized and the $\mathrm{R} \rightarrow \mathrm{B} 19^{\prime}$ is significantly suppressed, showing a very broad exothermal peak. The blurring of the exothermal peak corresponding to $\mathrm{R} \rightarrow \mathrm{B} 19^{\prime}$ is due to the particle distribution inhomogeneity and to the extended temperature range of this transformation as $R_{1}, R_{2} \rightarrow B 19^{\prime}$. The latent heat of this peak is $3.3 \mathrm{~J} \mathrm{~g}^{-1}$. We cannot exclude the implementation in a number of nanograins of the direct transformation $\mathrm{B} 2 \rightarrow \mathrm{B} 19^{\prime}$. On heating, two merging peaks corresponding to successive $\mathrm{B} 19^{\prime} \rightarrow \mathrm{R}$ and $\mathrm{R} \rightarrow \mathrm{B} 19^{\prime}$ transformations are observed (Figure 5). Though merging, the main peaks for the direct and reverse $\mathrm{B} 2 \leftrightarrow \mathrm{R}$ transformations on cooling and on heating are rather narrow and well identifiable, which makes it possible to determine the temperature hysteresis as $5.6^{\circ} \mathrm{C}$. The small hysteresis confirms the correspondence of these peaks to $\mathrm{B} 2 \leftrightarrow \mathrm{R}$ transformation. The results obtained for NC Ti-50.9Ni alloy after aging under conditions of intense $\mathrm{Ti}_{3} \mathrm{Ni}_{4}$ precipitation are consistent with the Table 1 and TEM data, according to which $T_{R}$ is $33^{\circ} \mathrm{C}$ and the alloy is in the B2 + R state.

Thus, we can assume that the broad $\mathrm{B} 2 \rightarrow \mathrm{R}$ peak upon cooling contains two peaks corresponding to the $\mathrm{B} 2 \rightarrow \mathrm{R}_{1}$ and $\mathrm{B} 2 \rightarrow \mathrm{R}_{2}$ transformations. The TEM analysis results allow us to interpret these peaks as follows: (i) first, the transformation $B 2 \rightarrow R_{1}$, which is characterized by quite high and narrow peaks developing in the substructure prevailing in the volume of the grain-subgrain nanostructure; (ii) then, there is a temperature-extended transformation of $\mathrm{B} 2 \rightarrow \mathrm{R}$ in groups of nanograins, which is designated as $\mathrm{B} 2 \rightarrow \mathrm{R} 2$. 


\section{Discussion}

Aging at different temperatures is found to provide coherent precipitation of $\mathrm{Ti}_{3} \mathrm{Ni}_{4}$ particles differing in size, morphology, and spatial distribution in grain-subgrain structure and cause different variations to the transformation behavior of NC Ti-50.9Ni alloy. After aging at $300{ }^{\circ} \mathrm{C}$, coherent particles precipitate mainly in the subgrain structure at dislocations. At the same time, $\mathrm{Ti}_{3} \mathrm{Ni}_{4}$ particles are not observed in dislocation-free nanograins but precipitate in nanograins, including those with a size less than $100 \mathrm{~nm}$ in the case of the presence of dislocations in them. Thus, the initial non-uniform grain-subgrain structure of the NC Ti-50.9Ni alloy causes an inhomogeneous distribution of both $\mathrm{Ti}_{3} \mathrm{Ni}_{4}$ precipitates and dislocations in the nanostructure. We believe that the reason for this precipitation behavior during aging at $300{ }^{\circ} \mathrm{C}$ lies in the features of the initial NC structure formation after severe cold deformation.

As noted above, two types of nanograins can be distinguished in the NC TiNi grainsubgrain structure: dislocation-containing nanograins formed under deformation and dislocation-free nanograins crystallized from amorphous state [10,11]. Unfortunately, it is impossible to determine with a sufficient degree of reliability in each case the type of observed nanograins without a special study. Reasoning from our analysis, the absence of $\mathrm{Ti}_{3} \mathrm{Ni}_{4}$ particles in dislocation-free nanograins suggests that their precipitation during low-temperature aging needs such defects as dislocations [12,13]. This conclusion agrees with data [19] showing that TiNi nanograins crystallized from an amorphous state are unfavorable for $\mathrm{Ti}_{3} \mathrm{Ni}_{4}$ precipitation in terms of the energy requirements energy due to the release of stored energy and in terms of chemical composition. In addition, the R-phase which usually nucleates at the interfaces between the particle and the matrix $[2,6,20]$ is not detected in dislocation-free nanograins, which is consistent with the absence of coherent $\mathrm{Ti}_{3} \mathrm{Ni}_{4}$ particles in such nanograins.

It was found that with an increase in the aging temperature to $400{ }^{\circ} \mathrm{C}$ and the diffusion mobility of $\mathrm{Ni}$ atoms, the size of $\mathrm{Ti}_{3} \mathrm{Ni}_{4}$ nanoparticles increases, their shape changes from spherical to lenticular, and the spatial distribution in the nanostructure changes from location at dislocations to precipitation at subboundaries. No aging effects were found in nanograins. It is believed that the suppression of the deposition of coherent particles is provided by geometric constraints on the side of high-angle boundaries, which prevent the formation of arrays of self-accommodated lenticular particles inside nanocrystalline grains $[5,6]$. Thus, the presence of different types of internal boundaries (low-angle and high-angle) in the grain-subgrain TiNi nanostructure is the main factor affecting the process of heterogeneous nucleation of coherent $\mathrm{Ti}_{3} \mathrm{Ni}_{4}$ particles at temperatures of intense decomposition of the B2 solid solution. Such precipitates emerge in the region of low-angle subboundaries and are not found in nanograins with high-angle boundaries.

Note that the precipitation of $\mathrm{Ti}_{3} \mathrm{Ni}_{4}$ particles and the corresponding appearance of the R-phase upon annealing at $400{ }^{\circ} \mathrm{C}$ are accompanied by a shift in the characteristic temperatures of martensitic transformation (Table 1). It is consistent with the general regularities of the evolution of the structural-phase state with a change in aging temperature that are obtained for polycrystalline Ni-rich TiNi alloys [2-7,18-20]. At the same time, there are some features of the multistage martensitic transformations in the NC Ti-50.9Ni alloy due to the inhomogeneous $\mathrm{Ti}_{3} \mathrm{Ni}_{4}$ particles precipitation.

Various hypotheses of the mechanisms of this phenomenon have been proposed $[4-7,20]$. In polycrystalline TiNi-based alloys, two types of inhomogeneity can change the sequence of martensite transformations: (i) local inhomogeneities of Ni concentrations and internal stresses near coherent $\mathrm{Ti}_{3} \mathrm{Ni}_{4}$ particles and (ii) microscopic heterogeneity due to the different nature of the decomposition of the B2-solid solution TiNi between the region of grain boundaries and their internal volume $[4-7,18,20]$. The most probable cause of multistage transformations is the presence of zones differing in size and particle distribution [18]. The inhomogeneity of the distribution of $\mathrm{Ti}_{3} \mathrm{Ni}_{4}$ particles within the grains provides a difference in the concentration of $\mathrm{Ni}$ in the B2-austenite within the boundaries and in the internal volume of the grains. As a result, the $\mathrm{B} 2 \leftrightarrow \mathrm{R}$ transformation first occurs at the 
grain boundary with a low $\mathrm{Ni}$ content, and then inside the grains with a higher Ni content, which gives rise to the abnormal three-stage martensitic transformation [4-7].

Evidently, the grain size determines the ratio between the volume fractions of grain boundaries and grain volumes and can thus influence the $\mathrm{Ti}_{3} \mathrm{Ni}_{4}$ distribution and martensite transformations in aged specimens [7,20-22]. Note that according to [23], the size of nickel-depleted zones near the particle-matrix interface varies from 20 to $100 \mathrm{~nm}$, depending on the particle size, which corresponds to the observed range of nanograin sizes and allows considering only local Ni concentration inhomogeneities. Thus, it is unclear what kind of inhomogeneity is responsible for the abnormal three-peak behavior of NC TiNi alloy under intensive aging at $400{ }^{\circ} \mathrm{C}$. At the same time, our analysis identifies inhomogeneities associated with different $\mathrm{Ti}_{3} \mathrm{Ni}_{4}$ precipitation behavior in substructural regions and groups of nanograins. After aging at $400{ }^{\circ} \mathrm{C}$, the $\mathrm{B} 2$ matrix of the Ti-50.9Ni $\mathrm{NC}$ alloy exhibits a difference in the Ni concentration in the substructural regions and groups of nanograins, and the scale of this inhomogeneity is much larger than the scale of local stresses and the $\mathrm{Ni}$ concentration near $\mathrm{Ti}_{3} \mathrm{Ni}_{4}$ particles. In this case, an anomalous $R$-phase transformation effect is possible: higher temperature transformations $B 2 \leftrightarrow R_{1}$ in substructural regions with $\mathrm{Ti}_{3} \mathrm{Ni}_{4}$ particles and lower temperature transformations $\mathrm{B} 2 \leftrightarrow \mathrm{R}_{2}$ in nanograins free of $\mathrm{Ti}_{3} \mathrm{Ni}_{4}$. This is consistent with the expectation of $\mathrm{Ni}$ content depletion in the matrix as Ni-rich precipitation progresses. We believe that the joint occurrence of the two transformation streams is due to the heterogeneity of the grain-subgrain nanostructure of Ti-50.9Ni NC alloy. The study of martensitic transformations by the DSC method made it possible to confirm these assumptions (Figure 5).

\section{Conclusions}

Electron microscopy analysis of the size and morphology of coherent $\mathrm{Ti}_{3} \mathrm{Ni}_{4}$ precipitates in grain-subgrain NC Ti-50.9Ni alloy aged at $300^{\circ} \mathrm{C}$ and $400{ }^{\circ} \mathrm{C}$ is performed.

It was shown that on aging at $300{ }^{\circ} \mathrm{C}$, spherical $\mathrm{Ti}_{3} \mathrm{Ni}_{4}$ particles smaller than $10 \mathrm{~nm}$ precipitate at dislocations in the alloy substructure. Such particles are found in dislocationcontaining nanograins and are not found in dislocation-free nanograins.

On aging at $400{ }^{\circ} \mathrm{C}$, the $\mathrm{Ti}_{3} \mathrm{Ni}_{4}$ particles increase in size, changing their shape from spherical to near lenticular and their distribution within the nanostructure from location at dislocations to precipitation at subboundaries. The presence of different types of internal boundaries in Ti- $50.9 \mathrm{Ni}$ is the main factor that influences the inhomogeneous nucleation of coherent $\mathrm{Ti}_{3} \mathrm{Ni}_{4}$ particles in the temperature range of their intense precipitation at $400{ }^{\circ} \mathrm{C}$. Such particles nucleate at low-angle sub-boundaries, while decomposition of B2-austenite is not observed in nanograins with high-angle boundaries.

$\mathrm{The}_{3} \mathrm{Ni}_{4}$ distribution inhomogeneity in NC Ti-50.9Ni provides different structuralphase states in the grain-subgrain nanostructure and accordingly different Ni concentrations in subgrains and nanograins regions. This is one of the driving factors responsible for the occurrence of the anomalous R-phase transformation effect in the sequence of multistage martensitic transformations $\mathrm{B} 2 \leftrightarrow \mathrm{R} \leftrightarrow \mathrm{B} 19^{\prime}$.

The results reported can help in choosing appropriate thermal and thermomechanical treatment modes for Ni-rich TiNi alloys to improve their performance as cardiovascular implant materials.

Author Contributions: Conceptualization, T.M.P. and A.I.L.; methodology, T.M.P. and S.L.G.; investigation, S.L.G. and N.V.G.; writing—original draft preparation, T.M.P.; writing—review and editing, T.M.P. and. S.L.G.; project administration, A.I.L. and. A.N.K. All authors have read and agreed to the published version of the manuscript.

Funding: This research was performed under State Assignment for ISPMS SB RAS (project No. FWRW-2021-0004).

Institutional Review Board Statement: Not applicable.

Informed Consent Statement: Not applicable. 
Data Availability Statement: Data are available from the corresponding author on reasonable request.

Conflicts of Interest: The authors declare no conflict of interest.

\section{References}

1. Elahinia, M.H.; Hashemi, M.; Tabesh, M.; Bhaduri, S.B. Manufacturing and processing of NiTi implants: A review. Prog. Mater. Sci. 2012, 57, 911-946. [CrossRef]

2. Otsuka, K.; Ren, X. Physical metallurgy of TiNi-based shape memory alloys. Prog. Mater. Sci. 2005, 50, 511-678. [CrossRef]

3. Zheng, Y.; Jiang, F.; Li, L.; Yang, H.; Liu, Y. Effect of ageing treatment on the transformation behaviour of Ti-50.9 at.\% Ni alloy. Acta Mater. 2010, 58, 3444-3458. [CrossRef]

4. Fan, G.L.; Chen, W.; Yang, S.; Zhu, J.H.; Ren, X.B.; Otsuka, K. Origin of abnormal multi-stage martensitic transformation behavior in aged Ni-rich TiNi shape memory alloys. Acta Mater. 2004, 52, 4351-4362. [CrossRef]

5. Khalil-Allafi, J.; Dlouhý, A.; Eggeler, G. $\mathrm{Ni}_{4} \mathrm{Ti}_{3}$-precipitation during aging of NiTi shape memory alloys and its influence on martensitic phase transformations. Acta Mater. 2002, 50, 4255-4274. [CrossRef]

6. Khalil-Allafi, J.; Ren, X.; Eggeler, G. The mechanism of multistage martensitic transformations in aged Ni-rich NiTi shape memory alloys. Acta Mater. 2002, 50, 793-803. [CrossRef]

7. Wang, X.; Kustov, S.; Li, K.; Schryvers, D.; Verlinden, B.; Van Humbeeck, J. Effect of nanoprecipitates on the transformation behavior and functional properties of a Ti-50.8 at.\% Ni alloy with micron-sized grains. Acta Mater. 2015, 82, 224-233. [CrossRef]

8. Waitz, T.; Kazykhanov, V.; Karnthaler, H.P. Martensitic phase transformations in nanocrystalline NiTi studied by TEM. Acta Mater. 2004, 52, 137-147. [CrossRef]

9. Prokofiev, E.A.; Burow, A.; Payton, E.; Bhaduri, S. Suppression of $\mathrm{Ni}_{4} \mathrm{Ti}_{3}$ precipitation by grain size refinement in Ni-rich NiTi shape memory alloys. Mem. Alloys Adv. Eng. Mater. 2010, 12, 747-753. [CrossRef]

10. Prokoshkin, S.; Brailovski, V.; Dubinskiy, S.; Inaekyan, K.; Kreitcberg, A. Gradation of nanostructures in cold-rolled and annealed Ti-Ni shape memory alloys. Shap. Mem. Superelasticity 2016, 2, 12-17. [CrossRef]

11. Prokoshkin, S.; Dubinskiy, S.; Brailovski. Features of a nanosubgrained structure in deformed and annealed Ti-Ni SMA: A Brief Review. Shap. Mem. Superelasticity 2019, 5, 336-345. [CrossRef]

12. Nishida, M.; Wayman, C.M.; Honma, T. Precipitation processes in near-equiatomic TiNi shape memory alloys. Metall. Trans. 1986, A17, 1505-1555. [CrossRef]

13. Kim, J.I.; Miyazaki, S. Effect of nano-scaled precipitates on shape memory behavior of Ti-50.9 at. \% Ni alloy. Acta Mater. 2005, 53, 4545-4554. [CrossRef]

14. Valiev, R.Z.; Islamgaliev, R.K.; Alexandrov, I.V. Bulk nanostructured materials from severe plastic deformation. Prog. Mater. Sci. 2000, 45, 911-946. [CrossRef]

15. Sauvage, X.; Wilde, G.; Divinski, S.V.; Horitac, Z.; Valiev, R.Z. Grain boundaries in ultrafine grained materials processed by severe plastic deformation and related phenomena. Mater. Sci. Eng. A 2012, 540, 1-12. [CrossRef]

16. Pelton, A.R.; Russell, S.M.; DiCello, J. The physical metallurgy of nitinol for medical applications. JOM 2003, 55, 33-37. [CrossRef]

17. Cao, S.; Ke, C.B.; Zhang, X.P.; Schryvers, D. Morphological characterization and distribution of autocatalytic-grown $\mathrm{Ni}_{4} \mathrm{Ti}_{3}$ precipitates in a NiTi single crystal. J. Alloys Compd. 2013, 577, 215-218. [CrossRef]

18. Karbakhsh Ravari, B.; Farjami, S.; Nishida, M. Effects of Ni concentration and aging conditions on multistage martensitic transformation in aged Ni-rich Ti-Ni alloys. Acta Mater. 2014, 69, 17-29. [CrossRef]

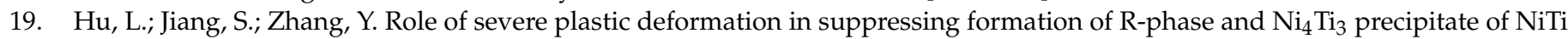
shape memory alloy. Metals 2017, 7, 145. [CrossRef]

20. Dlouhy, A.; Khalil-Allafi, J.; Eggeler, G. Multiple-step martensitic transformations in Ni-rich NiTi alloys-An in situ transmission electron microscopy investigation. Phil. Mag. 2003, 83, 339-363. [CrossRef]

21. Zhou, Y.; Zhang, J.; Fan, G.; Ding, X.; Sun, J.; Ren, X.; Otsuka, K. Origin of 2-stage R-phase transformation in low-temperature aged Ni-rich Ti-Ni alloys. Acta Mater. 2005, 53, 5365-5377. [CrossRef]

22. Wang, X.; Verlinden, B.; Van Humbeeck, J. Effect of post-deformation annealing on the R-phase transformation temperatures in NiTi shape memory alloys. Intermetallics 2015, 62, 43-49. [CrossRef]

23. Yang, Z.; Tirry, W.; Schryvers, D. Analytical TEM investigations on concentration gradients surrounding $\mathrm{Ni}_{4} \mathrm{Ti}_{3}$ precipitates in NiTi shape memory material. Scr. Mater. 2005, 52, 1129-1134. [CrossRef] 